\title{
Comparative study of high flow nasal catheter device and noninvasive positive pressure ventilation for sequential treatment in sepsis patients after weaning from mechanical ventilation in intensive care unit
}

\author{
Lizhen Xuan ${ }^{1 \#}$, Jiefei Ma ${ }^{1 \#}$, Jiale Tao ${ }^{1}$, Ling $Z_{\text {Zhu }}{ }^{1}$, Shilong Lin ${ }^{1}$, Song Chen ${ }^{1}$, Simeng Pan ${ }^{1}$, Duming Zhu ${ }^{1}$, \\ Lei Yi' ${ }^{2}$, Yijun Zheng ${ }^{1}$ \\ ${ }^{1}$ Department of Critical Care Medicine, Zhongshan Hospital, Fudan University, Shanghai, China; ${ }^{2}$ Department of Burn and Plastic Surgery, Ruijin \\ Hospital, Shanghai Jiao Tong University School of Medicine, Shanghai, China \\ Contributions: (I) Conception and design: L Xuan, J Ma, J Tao, L Yi, Y Zheng; (II) Administrative support: L Zhu, S Lin, S Chen, S Pan, D Zhu; (III) \\ Provision of study materials or patients: L Xuan, J Ma, L Yi, Y Zheng; (IV) Collection and assembly of data: L Xuan, J MA, J Tao, L Zhu, S Pan; (V) \\ Data analysis and interpretation: S Lin, S Chen, D Zhu; (VI) Manuscript writing: All authors; (VII) Final approval of manuscript: All authors. \\ "These authors contributed equally to this work. \\ Correspondence to: Dr. Yijun Zheng. Department of Critical Care Medicine, Zhongshan Hospital, Fudan University, 180 Fenglin Road, Xuhui District, \\ Shanghai, China. Email: Elisa525@126.com; Dr. Lei Yi. Department of Burn and Plastic Surgery, Ruijin Hospital, Shanghai Jiao Tong University, \\ School of Medicine, Shanghai, China. Email: 2457174068@qq.com.
}

\begin{abstract}
Background: The hypoxemia condition after mechanical ventilation (MV) weaning is not rare among sepsis patients, so we compared the efficacy in two different intervention groups: high-flow nasal cannula device group and non-invasive positive pressure ventilation (NPPV) group.

Methods: This is a retrospective cohort study. Participants were patients with sepsis receiving high-flow nasal catheter (HFNC) device or NPPV within 24 hours after weaning from MV. The primary outcome was tracheal re-intubation within 72 hours after extubation. Secondary outcomes included: oxygenation index, complication rate, patient comfort evaluation, HFNC/NPPV treatment time, ICU length of stay (LOS), ICU mortality, and in-hospital 28-day mortality.

Results: A total of 283 patients were included in the study with 167 in the HFNC group and 116 in the NPPV group. The re-intubation rates after extubation in both groups were respectively $4.2 \%$ and $5.2 \%$ without significant difference. Patients in the HFNC group experienced lower incidence of delirium, reflux aspiration, facial pressure ulcer and other complications, and higher score of patients comfort than that in the NPPV group. There was no significant difference in ICU LOS, ICU mortality and in-hospital 28-day mortality between the two groups.

Conclusions: HFNC and NPPV have similar efficacy in the sequential treatment of sepsis patients after weaning from MV. Compared with NPPV, those extubated to HFNC had lower rate of complications such as reflux aspiration and facial pressure ulcers. The patients extubation to HFNC is more comfortable (and associated with less delirium) than to NPPV.
\end{abstract}

Keywords: high-flow nasal catheter device; non-invasive positive pressure ventilation (NPPV); sepsis; mechanical ventilation (MV); ICU

Submitted Jan 02, 2021. Accepted for publication May 06, 2021.

doi: 10.21037/apm-21-8

View this article at: http://dx.doi.org/10.21037/apm-21-8 


\section{Introduction}

As a systemic infection led by multiple organ diseases, sepsis is a common complication of severe trauma, injury and major surgery. Its incidence is rising year after year, and the mortality rate in China is about $48.7 \%$ (1). Respiratory failure is a common organ failure in sepsis patients. It has been widely accepted that patients with severe hypoxemia should receive mechanical ventilation (MV) to improve tissue hypoxia. 2012 SSC guidelines have taken root, which advised for protective pulmonary ventilation strategies of lower plateau pressure $\left(\leq 30 \mathrm{cmH}_{2} \mathrm{O}\right)$, lower tidal volume (6 mL/kg), and allowance for hypercapnia, and proper positive end expiratory pressure to improve alveolar collapse. So far, however, no consensus had been reached on which method of oxygen therapy should be used after weaning from $M V$ in sepsis patients.

Traditional oxygen therapy (nasal catheter or mask oxygenation) and non-invasive positive pressure ventilation (NPPV) have been widely used as the pre-treatment and sequential treatment after weaning from $M V$ in septic hypoxemia. However, traditional oxygen therapy has poor efficacy in the treatment of hypoxemia, and NPPV is complex to implement with lower comfort and tolerance along with high incidence of complications such as reflux and aspiration, which limits its application. Recently, the clinical application of high flow nasal catheter (HFNC) device has received increasing attention. HFNC with simple operation, easy management, and high comfort and tolerance has become one of the main methods for treating patients with respiratory failure in the intensive care unit (ICU) (2). This study aimed at comparing the efficacy of HFNC and NPPV in sequential treatment after MV weaning in patients with sepsis in ICU, and at evaluating the value of $\mathrm{HFNC}$ in sequential therapy for $\mathrm{MV}$ in septic patients.

We present following article in accordance with the STROBE reporting checklist (available at http://dx.doi. org/10.21037/apm-21-8).

\section{Methods}

This study was a single-center retrospective cohort study, and it was approved by the Medical Ethics Committee of Zhongshan Hospital affiliated to Fudan University (No. B2018-015). The study was conducted in accordance with the Declaration of Helsinki (as revised in 2013). Individual consent for this retrospective analysis was waived.

\section{Participants}

Perioperative surgical patients with sepsis admitted to surgical ICU of Zhongshan Hospital affiliated to Fudan University from September 2013 to August 2017 who were treated with $M V$ and HFNC/NPPV therapy after weaning from $M V$ were enrolled.

Inclusion criteria: (I) $\geq 18$ and $\leq 85$ years old; (II) perioperative surgical patients who met diagnostic standards for sepsis (sepsis 3.0) (3), SOFA score >2; (III) ICU admission with $\mathrm{MV}$; (IV) met indications for weaning from MV (see below), passed the spontaneous breathing test and got successfully extubated; (V) HFNC/NPPV therapy was performed within $24 \mathrm{~h}$ after $\mathrm{MV}$ weaning.

Exclusion criteria: (I) received both HFNC and NPPV treatment; (II) uncontrolled surgical problems (such as hemorrhage or anastomotic fistula) after the first time of MV weaning; (III) GCS score <12; (IV) pregnant.

\section{Research methods}

The clinical data of patients who met the inclusion criteria were collected from the database of our institution (including history system, medical order system, nursing record list, respiratory record list, etc.).

All patients were treated according to the protocol of sepsis during hospitalization $(4,5)$. Daily assessments of patients were conducted by clinicians and respiratory therapists. Spontaneous breath tests ( $T$ tubes, 30-120 minutes) were given to patients who met the indications for weaning extubation, and tracheal intubation removed for those who passed spontaneous breath test (6). The weaning indications contain six parameters, when the patient meet all the statements, they can weaning from mechanical ventilation. Mask oxygenating was given after weaning (oxygen flow rate $5-8 \mathrm{~L} / \mathrm{min}$ ). Patients with hypoxemia $\left(\mathrm{PaO}_{2} / \mathrm{FiO}_{2}<250\right.$ or $\left.\mathrm{SpO}_{2}<95 \%\right)$ and/ or shortness of breath (respiratory rate $>25 \mathrm{bpm}$ ) were given HFNC or NPPV sequential treatment. The choice of treatment modality was determined by the availability of equipment and once used medical supplies when a patient was enrolled. Patients were divided into two groups according to the way of respiratory support after extubation: the HFNC group and the NPPV group.

\section{Indications for weaning from $M V$}

(I) Improvement in or removal of causes of MV; (II) 
hemodynamic stability: HR $<140 \mathrm{bpm}$, no significant hypotension (no need for or low dose applications of vasoactive drugs such as dopamine/dobutamine $<5 \mu \mathrm{g} / \mathrm{kg} / \mathrm{min}$ or norepinephrine $\leq 0.1 \mu \mathrm{g} / \mathrm{kg} / \mathrm{min}$ ); (III) no severe metabolic acidosis; (IV) oxygenation indexes: $\mathrm{SaO}_{2}>90 \%$ with $\mathrm{FiO}_{2} \leq 0.4$ (or $\mathrm{PaO}_{2} / \mathrm{FiO}_{2} \geq 150$ ), $\mathrm{PEEP} \leq 8 \mathrm{cmH}_{2} \mathrm{O}$; (V) respiratory rate $\geq 8 \mathrm{bpm}, \leq 35 \mathrm{bpm}$, shallow fast breathing index (RSBI) $<105 \mathrm{bpm} / \mathrm{L}$; no obvious respiratory acidosis; (VI) conscious, GCS score $\geq 12$ points, able to cough and remove airway secretions.

\section{HFNC/NPPV parameter settings}

The HFNC devices in our center were AIRVO2 (Fisher \& Paykel Healthcare, New Zealand, PT 101). Initial parameter settings: HFNC group inhalation oxygen concentration $40-60 \%$, oxygen flow $30-60 \mathrm{~L} / \mathrm{min}$, temperature $34{ }^{\circ} \mathrm{C}$. NPPV used nasal and oral non-invasive masks, ventilators models were Evita 2, 4 and XL (Dräger, Germany). Initial parameter settings: inhalation oxygen concentration $40-60 \%$, PEEP 5-10 $\mathrm{cmH}_{2} \mathrm{O}$. The respiratory therapy parameters were set by the clinical physician and respiratory therapist team based on the initial setting routine and adjusted according to patients' complaints, clinical manifestations, and changes in condition or blood gas analysis results.

\section{Indications for weaning from $\mathrm{HFNC/NPPV}$}

Weaning from HFNC/NPPV was defined as the maintenance of a $\mathrm{SpO}_{2}$ level of over $95 \%$ or a $\mathrm{PaO}_{2} / \mathrm{FiO}_{2}$ $>250$ with $\mathrm{FiO}_{2} \leq 0.4$ without any indication for HFNC/ NPPV. It represented well weaned if no supportive respiratory care was required for at least 24 hours after the resumption of general oxygen therapy.

\section{Indications for re-intubation}

Indications for reintubation included: respiratory arrest, respiratory pauses with loss of consciousness or gasping respiration, encephalopathy, cardiovascular instability, unmanageable secretions, clinical signs of exhaustion, refractory hypoxemia $\left(\mathrm{SpO}_{2}<90 \%\right.$ or $\mathrm{PaO}_{2}<60 \mathrm{mmHg}$ with $\mathrm{FiO}_{2} \geq 0.8$ ), or respiratory acidosis $[\mathrm{pH}<7.30$ and partial pressure of arterial carbon dioxide $\left(\mathrm{PaCO}_{2}\right) \geq 50 \mathrm{mmHg}$ (7). When this was the case, HFNC/NPPV treatment was considered unsuccessful and tracheal intubation was reperformed for mechanical ventilation.

\section{Indications for ICU discharge}

Primary disease controlled, hemodynamically stable (no antihypertensives), no severe arrhythmias, no severe acid-base balance disorders or water and electrolytes disorders, stable breathing remained for at 24 hours after weaning (general mask or nasal obstruction oxygenating), no requirement for special life monitoring and supporting, and complications controlled. When the above conditions were met, the decision to transfer out of ICU could be made by attending physicians.

\section{Outcomes and definitions}

Primary outcome: re-intubation rate within 72 hours after extubation.

Secondary outcomes:

(I) Prognostic indicators: ICU LOS, ICU mortality and in hospital 28-day mortality.

(II) Respiratory function parameters: respiratory rate, oxygenation index, $\mathrm{PaCO}_{2}, \mathrm{HFNC} / \mathrm{NPPV}$ sequential treatment time.

(III) Complications of other systems: delirium, reflux aspiration, abdominal distension, pneumothorax, facial pressure sores, etc. The judgment of delirium was made by a bedside responsible nurse every 8 hours for evaluation of CAM-ICU delirium (positive/negative) $(8,9)$ and was recorded on the nursing record sheet. A patient who had been positive for more than one record was deemed to have had delirium. Pressure ulcers were assessed every 8 hours by the bedside nurse ( 0 , none; 1 , local erythema; 2, moderate skin breakdown; 3 , skin ulcer; 4, skin necrosis). A score of 1 or more stood for pressure sores. The remaining indicators were assessed by respiratory therapists and attending physicians based on patients' complaints, symptoms, signs, and chest X-ray daily assessment, and recorded in the history or respiratory record list.

(IV) Comfort assessment (Patient Comfort Score): Visual analogue scale (VAS), 0-2 points for comfort, 3-4 points for mild discomfort, 5-6 points for moderate discomfort, 7-8 points for heavy discomfort, $9-10$ points for extremely discomfort. Patients were daily asked by respiratory therapists to subjectively tick the corresponding numbers to be recorded in respiratory treatment list. The highest value was used as the patient comfort score. 


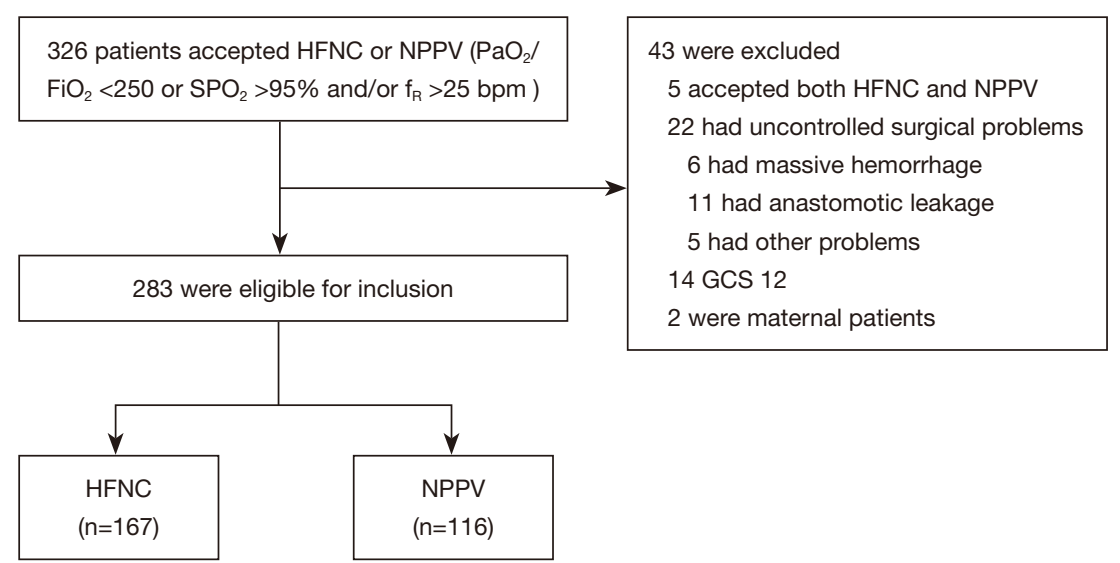

Figure 1 Patient selection flow chart. GCS, Glasgow Coma Scale; HFNC, high-flow nasal catheter device; NPPV, non-invasive positive pressure ventilation

\section{Statistical analysis}

SPSS 22.0 software (IBM Corporation, NY, USA) was used. All the data were tested for normality and homogeneity of variance before statistical test. If the data obeyed the normal distribution and the homogeneity of the variance, $t$-test would be chosen to compare the statistical differences among the variables in the group to show in mean \pm standard deviation $(\bar{x} \pm s)$. If the data did not obey the normal distribution and homogeneity of variance, the rank sum test would be used to show in the median. Cases and rates were used for count data, and chi-square test for comparison between groups. A P value $<0.05$ was considered statistically significant. GraphPad Prism 7 (GraphPad Software, San Diego, USA) was used for charting and graphing.

\section{Results}

\section{Clinical data}

A total number of 326 septic cases met the inclusion criteria were collected from September 2013 to August 2017 in this study. Among them, 5 patients received HFNC and NPPV earlier or later during the treatment, 22 patients had uncontrollable surgical problems after weaning from MV, 14 patients had different degrees of decreased consciousness (GCS score <12), and 2 patients were excluded for pregnant. The rest 283 patients were enrolled with 167 in the HFNC group and 116 in the NPPV group (Figure 1).

There was no significant difference between the two groups in demographic characteristics (age, sex, BMI, etc.), general clinical status at ICU admission, arterial blood gas indexes at extubation and before sequential therapy, APACHE II score, SOFA score, or invasive MV time before extubation (Table 1).

\section{Primary outcome and prognostic indicators}

There were no significant differences in re-intubation rates within 72 hours in patients in the HFNC group and the NPPV group (4.2\% vs. $5.2 \%, \mathrm{P}=0.698)$. Compared with the NPPV group, the sequential treatment time of the HFNC group was slightly shorter $(60.8 \pm 29.3$ vs. $75.6 \pm 36.1$, $\mathrm{P}=0.082)$. There was no significant difference in ICU mortality, in-hospital 28-day mortality, and ICU LOS between the two groups (Table 2).

\section{Respiratory outcomes}

There was no significant difference in respiratory rate, oxygenation index and $\mathrm{PaCO}_{2}$ between the two groups before initiating sequential therapy after weaning from $\mathrm{MV}$ ( $\mathrm{P}>0.05$, Figures 2-4).

Respiratory rate (Figure 2) in HFNC group at before treatment, 24 hours after and 48 hours after three points are higher than these in NPPV group without significant difference $(\mathrm{P}>0.05)$. The oxygenation index (Figure 3$)$ in HFNC and NPPV groups were improved after 24 and 48 hours of treatment. There is no significant difference when compared between two groups at three time points. No significant difference in $\mathrm{PaCO}_{2}$ before and after treatment between groups was found (Figure 4). 
Table 1 Demographic and clinical characteristics of patients in two groups

\begin{tabular}{|c|c|c|c|}
\hline Demographic and clinical characteristics & HFNC $(n=167)$ & NPPV $(n=116)$ & $P$ value \\
\hline Gender, n (\%) & & & 0.715 \\
\hline Male & $115(68.9)$ & $82(70.7)$ & \\
\hline Female & $52(31.1)$ & $34(29.3)$ & \\
\hline BMI $\left(\mathrm{kg} / \mathrm{m}^{2}\right)$ & $24.3 \pm 3.2$ & $25.6 \pm 3.0$ & 0.562 \\
\hline Post-operative sepsis, n (\%) & & & 0.437 \\
\hline Abdominal surgery & $83(49.7)$ & $60(51.7)$ & \\
\hline Chest surgery & $46(27.5)$ & $22(19.0)$ & \\
\hline Pelvic surgery & $3(1.8)$ & $1(0.9)$ & \\
\hline Hypertension & 55 (32.9) & $34(29.3)$ & \\
\hline Coronary artery disease & $24(14.4)$ & $11(9.5)$ & \\
\hline Diabetes mellitus & $19(11.4)$ & $10(8.6)$ & \\
\hline Cerebrovascular disease & $13(7.78)$ & $10(8.62)$ & \\
\hline COPD or asthma & $14(8.4)$ & $11(9.5)$ & \\
\hline Chronic heart failure & $5(3.0)$ & $5(4.3)$ & \\
\hline Renal insufficiency & $12(7.2)$ & $13(11.2)$ & \\
\hline Liver dysfunction & $9(5.4)$ & $6(5.2)$ & \\
\hline \multicolumn{4}{|l|}{ Arterial blood gas before sequential therapy } \\
\hline $\mathrm{pH}$ & $7.38 \pm 0.09$ & $7.42 \pm 0.13$ & 0.753 \\
\hline $\mathrm{PaO}_{2} / \mathrm{FiO}_{2}(\mathrm{mmHg})$ & $212 \pm 75$ & $207 \pm 81$ & 0.871 \\
\hline $\mathrm{PaCO}_{2}(\mathrm{mmHg})$ & $32 \pm 6$ & $30 \pm 5$ & 0.496 \\
\hline $\begin{array}{l}\text { Liquid balance } 24 \mathrm{~h} \text { before extubation } \\
\text { (Intake-discharge) }(\mathrm{mL})\end{array}$ & $-573 \pm 479$ & $-661 \pm 402$ & 0.537 \\
\hline CRRT, n (\%) & $8(4.8)$ & $3(2.6)$ & 0.398 \\
\hline APACHE II score (ICU check-in) & $17.8 \pm 5.1$ & $14.3 \pm 6.4$ & 0.758 \\
\hline SOFA score (ICU check-in) & $7.4 \pm 3.7$ & $5.9 \pm 3.3$ & 0.676 \\
\hline MV time before extubation (h) & $87.6 \pm 41.3$ & $96.1 \pm 50.4$ & 0.278 \\
\hline
\end{tabular}

*pre-operation category included patients with sepsis due to uncontrolled pulmonary infection, bloodstream infection and skin or soft tissue infection before they received surgeries. HFNC, high-flow nasal catheter device; NPPV, non-invasive positive pressure ventilation; $\mathrm{BMI}$, body mass index; COPD, chronic obstructive pulmonary disease; $\mathrm{Hb}$, hemoglobin; $\mathrm{PaO}_{2}$, arterial partial pressure of oxygen; FiO fraction of inspired oxygen; $\mathrm{PaCO}_{2}$, partial pressure of arterial carbon dioxide; CRRT, continuous renal replacement therapy; APACHE, acute physiology and chronic health evaluation; ICU, intensive care unit; SOFA, sepsis-related organ failure assessment; MV, mechanical ventilation. 
Table 2 Primary outcome and prognostic indicators in two groups

\begin{tabular}{|c|c|c|c|}
\hline Outcome and Prognostic indicators & HFNC $(n=167)$ & NPPV $(n=116)$ & $P$ value \\
\hline ICU stay time $(\mathrm{d})$ & $8.5 \pm 2.6$ & $9.9 \pm 3.1$ & 0.232 \\
\hline In-ICU morality, n (\%) & $18(10.8)$ & $15(12.9)$ & 0.579 \\
\hline In-hospital 28-day mortality, n (\%) & $21(12.6)$ & $17(14.7)$ & 0.614 \\
\hline
\end{tabular}

HFNC, high-flow nasal catheter device; NPPV, non-invasive positive pressure ventilation; ICU, intensive care unit.

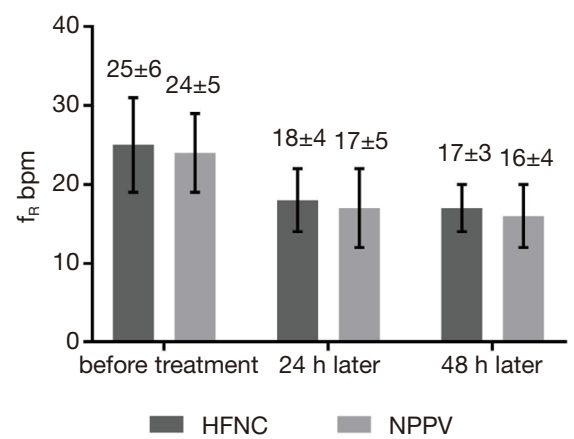

Figure 2 Respiratory rate in the HFNC and the NPPV groups. HFNC, high flow nasal catheter; NPPV, noninvasive positive pressure ventilation.

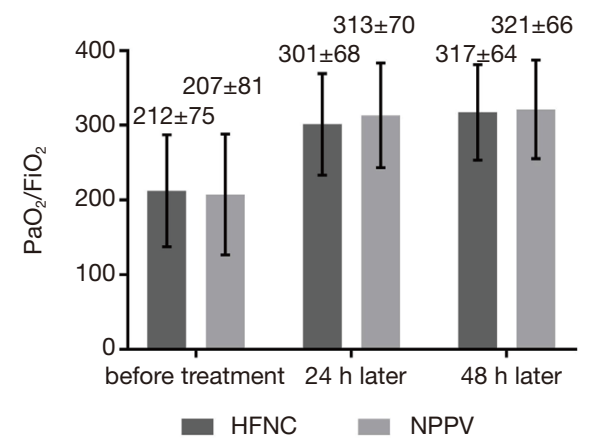

Figure 3 Oxygenation index in the HFNC and the NPPV groups. HFNC, high flow nasal catheter; NPPV, noninvasive positive pressure ventilation.

\section{Other complications and patient comfort scores}

Compared with the NPPV group, patients in the HFNC group had better comfort scores $(3.6 \pm 2.1$ vs. $6.9 \pm 3.7$, $\mathrm{P}=0.028)$, lower incidence of pneumothorax ( $0 \%$ vs. $1.7 \%$ $\mathrm{P}=0.326)$ and facial pressure ulcers $(0 \%$ vs. $26.7 \% \mathrm{P}<0.001)$,

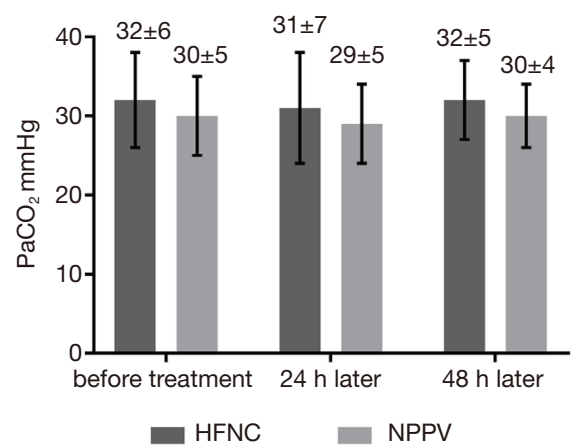

Figure $4 \mathrm{PaCO}_{2}$ in the HFNC and the NPPV groups. HFNC, high flow nasal catheter; NPPV, noninvasive positive pressure ventilation; $f_{R}$, frequency of respiration; GCS Glasgow Coma Scale.

and lower incidence of delirium and reflux aspiration $(\mathrm{P}<0.05)$ (Table 3). As we known, the NPPV ventilation method need facial mask to ensure the ventilation pressure which induced the facial pressure ulcer and the increased pressure may induce pneumothorax.

\section{Discussion}

It had been shown by studies (10-12) that as a model of respiratory support applied to patients with respiratory failure, HFNC is comparable to NPPV therapy which can significantly improve patient's pulmonary oxygenation function and correct hypoxemia. Compared with NPPV, HFNC can significantly reduce the incidence of pulmonary infection and regurgitation aspiration (11) without requiring for a closed ventilator circuit or leading to significant compression damage to patient's facial skin. In addition, HFNC is more accessible since it provides more comfort. However, no large-scale clinical study involving 
Table 3 Complications and patient comfort scores in two groups

\begin{tabular}{|c|c|c|c|}
\hline Complications and comfort scores & HFNC $(n=167)$ & NPPV $(n=116)$ & $P$ value \\
\hline Delirium, n (\%) & $21(12.6)$ & $25(21.6)$ & 0.044 \\
\hline Bloating, n (\%) & $6(3.6)$ & $10(8.6)$ & 0.072 \\
\hline Aspiration reflux, $\mathrm{n}(\%)$ & $3(1.8)$ & $8(6.9)$ & 0.029 \\
\hline Facial pressure ulcers, $\mathrm{n}(\%)$ & 0 & $31(26.7)$ & $<0.001$ \\
\hline
\end{tabular}

HFNC, high-flow nasal catheter device; NPPV, non-invasive positive pressure ventilation.

the application of HFNC in the sequential treatment of patients with sepsis after $M V$ weaning had been published.

It was shown in our single-center retrospective study that sequential treatment of hypoxemia with HFNC for sepsis patients after $M V$ weaning was not less effective than NPPV with lower incidence of complications and better comfort and tolerance.

Re-intubation rates within 72 hours, and secondary outcomes including ICU LOS, in-hospital 28-day mortality, ICU mortality, sequential treatment time, respiratory rate, oxygenation index and $\mathrm{PaCO}_{2}$ showed no significant difference in our study, which was similar to the result published by Frat et al. (13) and Hernández et al. $(14,15)$. In our study, re-intubation rates in HFNC group and NPPV group were $4.2 \%$ and $5.2 \%$ respectively, which were $10-20 \%$ lower than other studies (14-16), while ICU mortality and in-hospital 28-day mortality (less than $15 \%)$ were also significantly lower than other studies $(40-60 \%)(17,18)$. This might be due to most of sepsis patients admitted to our center were caused by primary surgical diseases such as biliary tract diseases, digestive tract perforation or intestinal obstruction that could be promptly relieved after surgery and drainage with good overall prognosis. And patients with uncontrolled surgical problems that occurred after mechanical ventilation weaning were excluded in our study, which led to lower overall mortality and re-intubation rate.

It was also suggested that HFNC has better patient comfort and lower incidences of complications such as reflux aspiration and facial pressure ulcers than NPPV, which was similar to previous studies. Delirium as one of the most common mental disorders in septic patients had a significantly lower incidence in the HFNC group than that in the NPPV group (12.6\% vs. $21.6 \%, \mathrm{P}=0.044)$. Recent studies have shown that the incidence of delirium in ICU sepsis patients is as high as $70 \%$, which seriously affects the prognosis of sepsis $(19,20)$. The pathogenesis of delirium has not been fully elucidated, and the risk factors include severity of the disease, sedative and analgesic drugs, mechanical ventilation, high blood pressure, painful stimulation and sleep deprivation (9). The incidence of delirium in this study was significantly lower than that in previous studies, which might be due to the timely control of etiology, reduced mechanical ventilation time and the use of sedative drugs. And HFNC group patients whose better comfort did not affect sleep had significantly lower occurrence of delirium than the NPPV group worth further exploration.

\section{Limitations}

There were several limits in this study. First, this was a single-center study with a relatively small sample size, resulting in relatively low number of patients with complications. Second, the method of assigning patients to different groups was based on the availability of equipment and might lead in selection bias. Third, the prognosis of sepsis patients might bias according to the primary disease, treatment, basic status of patients and other aspects. Fourth, this study only compared the application of HFNC or NPPV along. Because the number of patients both receiving HFNC and NPPV in this study was too small (only 5 patients) to be analyzed, the combination group of HFNC+NPPV was excluded. For patients who need to maintain a certain PEEP but are not able to receive NPPV for long periods of time, the use of HFNC during intermittent NPPV treatment may result in different outcomes, which need a well-designed prospective randomized controlled trial to compare the efficacy of the combination therapy with HFNC alone or NPPV alone in 
the future.

\section{Conclusions}

In summary, the results of this study suggested that sequential treatment of hypoxemia with HFNC for patients with sepsis after weaning from MV is comparable to NPPV in extubation failure rate with a lower complication rate as well as better comfort and tolerance. Thus, HFNC has superior application prospects in the sequential treatment after MV weaning in septic patients.

\section{Acknowledgments}

Funding: Our study was supported by the National Natural Science Foundation of China (81971832) and Natural Science Foundation of Shanghai (19ZR1432100).

\section{Footnote}

Reporting Checklist: The authors have completed the STROBE reporting checklist. Available at http://dx.doi. org/10.21037/apm-21-8

Data Sharing Statement: Available at http://dx.doi. org/10.21037/apm-21-8

Conflicts of Interest: All authors have completed the ICMJE uniform disclosure form (available at http://dx.doi. org/10.21037/apm-21-8). The authors have no conflicts of interest to declare.

Ethical Statement: The authors are accountable for all aspects of the work in ensuring that questions related to the accuracy or integrity of any part of the work are appropriately investigated and resolved. This study was approved by the Medical Ethics Committee of Zhongshan Hospital affiliated to Fudan University (No. B2018015). The study was conducted in accordance with the Declaration of Helsinki (as revised in 2013). Individual consent for this retrospective analysis was waived.

Open Access Statement: This is an Open Access article distributed in accordance with the Creative Commons Attribution-NonCommercial-NoDerivs 4.0 International License (CC BY-NC-ND 4.0), which permits the noncommercial replication and distribution of the article with the strict proviso that no changes or edits are made and the original work is properly cited (including links to both the formal publication through the relevant DOI and the license). See: https://creativecommons.org/licenses/by-nc-nd/4.0/.

\section{References}

1. Cheng B, Xie G, Yao S, et al. Epidemiology of severe sepsis in critically ill surgical patients in 10 university hospitals in China. Crit Care Med 2007;35:2538-46.

2. Parke RL, McGuinness SP, Eccleston ML. A preliminary randomized controlled trial to assess effectiveness of nasal high-flow oxygen in intensive care patients. Respir Care 2011;56:265-70.

3. Singer M, Deutschman CS, Seymour CW, et al. The Third International Consensus Definitions for Sepsis and Septic Shock (Sepsis-3). JAMA 2016;315:801-10.

4. Dellinger RP, Levy MM, Rhodes A, et al. Surviving Sepsis Campaign: international guidelines for management of severe sepsis and septic shock, 2012. Intensive Care Med 2013;39:165-228.

5. Rhodes A, Evans LE, Alhazzani W, et al. Surviving Sepsis Campaign: International Guidelines for Management of Severe Sepsis and Septic Shock 2016. Intensive Care Med 2017;43:304-77.

6. Boles JM, Bion J, Connors A, et al. Weaning from Mechanical Ventilation. Eur Respir J 2007;29:1033-56.

7. Riviere S, Monconduit J, Zarka V, et al. Failure of noninvasive ventilation after lung surgery: a comprehensive analysis of incidence and possible risk factors. Eur J Cardiothorac Surg 2011;39:769-76.

8. Ely EW, Inouye SK, Bernard GR, et al. Delirium in mechanically ventilated patients: Validity and reliability of the confusion assessment method for the intensive care unit (CAM-ICU). JAMA 2001;286:2703-10.

9. Barr J, Fraser GL, Puntillo K, et al. Clinical Practice Guidelines for the Management of Pain, Agitation, and Delirium in Adult Patients in the Intensive Care Unit. Crit Care Med 2013;41:263-306.

10. Vourc'h M, Asfar P, Volteau C, et al. High-flow nasal cannula oxygen during endotracheal intubation in hypoxemic patients: a randomized controlled clinical trial. Intensive Care Med 2015;41:1538-48.

11. Frat JP, Brugiere B, Ragot $S$, et al. Sequential application of oxygen therapy via high-flow nasal cannula and noninvasive ventilation in acute respiratory failure: an observational pilot study. Respir Care 2015;60:170-8.

12. Lenglet H, Sztrymf B, Leroy C, et al. Humidified high flow nasal oxygen during respiratory failure in the 
emergency department: feasibility and efficacy. Respir Care 2012;57:1873-8.

13. Frat JP, Thille AW, Mercat A, et al. High-Flow Oxygen through Nasal Cannula in Acute Hypoxemic Respiratory Failure. N Engl J Med 2015;372:2185-96.

14. Hernández G, Vaquero C, Colinas L, et al. Effect of postextubation high-flow nasal cannula vs noninvasive ventilation on reintubation and postextubation respiratory failure in high-risk patients: a randomized clinical trial. JAMA 2016;316:1565-74.

15. Hernández G, Vaquero C, Gonzalez P, et al. Effect of postextubation high-flow nasal cannula vs conventional oxygen therapy on reintubation in low-risk patients: a randomized clinical trial. JAMA 2016;315:1354-61.

16. Zhao H, Wang H, Sun F, et al. High-flow nasal cannula oxygen therapy is superior to conventional oxygen therapy but not to noninvasive mechanical ventilation on intubation rate: a systematic review and meta-analysis. Crit Care 2017;21:184.

17. Stéphan F, Barrucand B, Petit P, et al. High-Flow Nasal Oxygen vs Noninvasive Positive Airway Pressure in Hypoxemic Patients After Cardiothoracic Surgery: A Randomized Clinical Trial. JAMA 2015;313:2331-9.

18. Vargas F, Saint-Leger M, Boyer A, et al. Physiologic Effects of High-Flow Nasal Cannula Oxygen in Critical Care Subjects. Respir Care 2015;60:1369-76.

19. Ebersoldt M, Sharshar T, Annane D. Sepsis-associated delirium. Intensive Care Med 2007;33:941-50.

20. Gofton TE, Young GB, Sepsis-associated encephalopathy. Nat Rev Neurol 2012;8:557-66.

Cite this article as: Xuan L, Ma J, Tao J, Zhu L, Lin S, Chen S, Pan S, Zhu D, Yi L, Zheng Y. Comparative study of high flow nasal catheter device and noninvasive positive pressure ventilation for sequential treatment in sepsis patients after weaning from mechanical ventilation in intensive care unit. Ann Palliat Med 2021;10(6):6270-6278. doi: 10.21037/apm-21-8 